\title{
ATP and NADPH engineering of Escherichia coli to improve the production of 4-hydroxyphenylacetic acid using CRISPRi
}

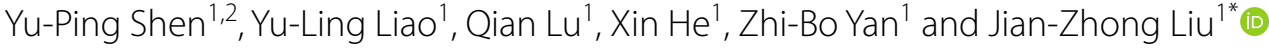

\begin{abstract}
Background: 4-Hydroxyphenylacetic acid (4HPAA) is an important raw material for the synthesis of drugs, pesticides and biochemicals. Microbial biotechnology would be an attractive approach for 4HPAA production, and cofactors play an important role in biosynthesis.

Results: We developed a novel strategy called cofactor engineering based on clustered regularly interspaced short palindromic repeat interference (CRISPRi) screening (CECRiS) for improving NADPH and/or ATP availability, enhancing the production of 4HPAA. All NADPH-consuming and ATP-consuming enzyme-encoding genes of E. coli were repressed through CRISPRi. After CRISPRi screening, 6 NADPH-consuming and 19 ATP-consuming enzyme-encoding genes were identified. The deletion of the NADPH-consuming enzyme-encoding gene yahK and the ATP-consuming enzyme-encoding gene fecE increased the production of 4HPAA from 6.32 to $7.76 \mathrm{~g} / \mathrm{L}$. Automatically downregulating the expression of the $p a b A$ gene using the Esa- $P_{\text {esas }}$ quorum-sensing-repressing system further improved the production of 4HPAA. The final strain E. coli 4HPAA- $\triangle$ yfp produced $28.57 \mathrm{~g} / \mathrm{L}$ of $4 \mathrm{HPAA}$ with a yield of $27.64 \%(\mathrm{~mol} / \mathrm{mol})$ in $2-\mathrm{L}$ bioreactor fed-batch fermentations. The titer and yield are the highest values to date.
\end{abstract}

Conclusion: This CECRiS strategy will be useful in engineering microorganisms for the high-level production of bioproducts.

Keywords: 4-Hydroxyphenylacetic acid, ATP engineering, NADPH engineering, CRISPRi, Escherichia coli

\section{Background}

4-Hydroxyphenylacetic acid (4HPAA), a valuable natural aromatic compound, has attracted much attention due to its numerous applications. 4HPAA is used in the synthesis of penicillin G, atenolol, benzoprofen, pesticides, etc. $[1,2]$. 4HPAA is an effective ingredient of Rhodiola rosea [2] and the Chinese herbs Aster tataricus (fan hun cao). A. tataricus is widely used in the treatment of

\footnotetext{
*Correspondence: Issljz@mail.sysu.edu.cn

${ }^{1}$ Institute of Synthetic Biology, Biomedical Center, Guangdong Province Key Laboratory of Improved Variety Reproduction in Aquatic Economic Animals, School of Life Sciences, Sun Yat-Sen University, Guangzhou 510275, People's Republic of China

Full list of author information is available at the end of the article
}

pneumonia, HBV and carcinomas in China [3-5]. Furthermore, 4HPAA has anxiolytic [6], antiplatelet [7] and hepatoprotective [8] properties. Moreover, 4HPAA is considered to be a potential hypopigmenting agent [9] and an inhibitor of hypertonicity and hypoxia [10].

4HPAA can be produced by chemical synthesis [11, 12]. However, this is energy intensive, environmentally unfriendly and expensive. To meet increasing market demand, heterologous biosynthesis in engineered microorganisms using synthetic biology and metabolic engineering provides an alternative way to produce 4HPAA. Koma et al. constructed Escherichia coli for the de novo production of 4HPAA from glucose by the overexpression of the Azospirillum brasilense NBRC102289 indole-3-pyruvate/phenylpyruvate 
decarboxylase gene ipdC and $E$. coli phenylacetaldehyde dehydrogenase gene $f e a B$ in a tyrosine-overproducing E. coli strain [1]. In our previous paper [13], applying a combinatorial strategy of the directed evolution of pathway enzymes and quorum-sensing-based dynamic regulation of the pathway further improved the production of 4HPAA, which reached $17.39 \mathrm{~g} / \mathrm{L}$ in 2-L bioreactor fed-batch fermentation. However, the titer of 4HPAA in engineered microorganisms is much lower than that of other aromatic compounds [14]. Thus, further work is required to increase the production of 4HPAA.

The biosynthesis of metabolites often involves many oxidoreductases and kinases, which require cofactors, such as NADPH and ATP. For example, synthesizing one mol 4HPAA requires $2 \mathrm{~mol} \mathrm{ATP}$ and $1 \mathrm{~mol}$ NADPH (Additional file 1: Fig. S1). Engineering cofactor availability is a common strategy of metabolic engineering for achieving high yields and productivity of metabolites. In E. coli, the pentose phosphate pathway (PPP), tricarboxylic acid cycle (TCA), and transhydrogenase systems are the three major sources of NADPH regeneration. The modulation of the three pathways has become a common method for increasing NADPH availability $[15,16]$. Many ATP engineering strategies by metabolic engineering of pathways that generate or consume ATP have been successfully applied to the efficient production of chemicals [17]. However, these strategies may result in changes in the carbon central metabolism of E. coli.

In the E. coli genome, there are $80 \mathrm{NADPH}$-consuming and 400 ATP-consuming enzyme-encoding genes. Can the repression of these genes be used as a strategy for metabolic engineering? Recently, clustered regularly interspaced short palindromic repeat interference (CRISPRi) was developed for DNA sequencespecific gene regulation [18]. CRISPRi is a simple and useful tool for the downregulation of genes. It can effectively silence transcription elongation by targeting the promoter sequence or block transcription initiation by targeting the protein coding region (Additional file 1: Fig. S2). CRISPRi has been widely applied for metabolic engineering [18-23]. With the application of multiple gRNAs or a gRNA array, CRISPRi has been used for modulating multiple pathway genes simultaneously.

Thus, we developed a novel strategy called cofactor engineering based on CRISPRi screening (CECRiS). All NADPH-consuming and ATP-consuming enzymeencoding genes of $E$. coli were repressed through CRISPRi, and the target genes that should be modified were identified to enhance the production of 4HPAA.

\section{Results and discussion}

Effects of NADPH-consuming enzyme-encoding genes

In the $E$. coli genome, $80 \mathrm{NADPH}$-consuming enzymeencoding genes exist. To repress these genes, we constructed sgRNA-expressing plasmids of these genes and cotransferred with the dCas9* plasmid into the 4HPAA producer $E$. coli 4HPAA-2 for shake-flask analysis of 4HPAA production. The sgRNAs were designed to bind to the nontemplate DNA strands of the $5^{\prime}$ end of the gene (approximately 100 bp downstream of ATG) based on several previous studies [18, 21-23]. Strains expressing the sgRNA plasmids for paaC, paaA, paaE, paaZ, $p a a B$, panE, $p d x I$ and ribD could not grow (Additional file 1: Fig. S3), indicating that the repression of these genes significantly affected growth. Moreover, the repression levels of these genes using the sgRNAs targeting the $5^{\prime}$ end of the gene (approximately $100 \mathrm{bp}$ downstream of ATG) may be too high to grow. To obtain the strain expressing the sgRNA plasmids for these genes, the N20 sequence should be redesigned to target the middle or $3^{\prime}$ end of the gene to reduce the repression level. As shown in Fig. 1 and Additional file 1: Fig. S3, repression of the yahK, yqjH, queF, dusA, gdhA and curA genes improved the production of 4HPAA in E. coli 4HPAA-2 by 67.1, $45.6,11.9,10.0,6.8$ and 5.3\%, respectively. The yahK gene encodes NADPH-dependent aldehyde reductase, which catalyzes the reduction of a wide range of aldehydes into their corresponding alcohols. Koma et al. reported that YahK can convert 4-hydroxyphenylacetaldehyde

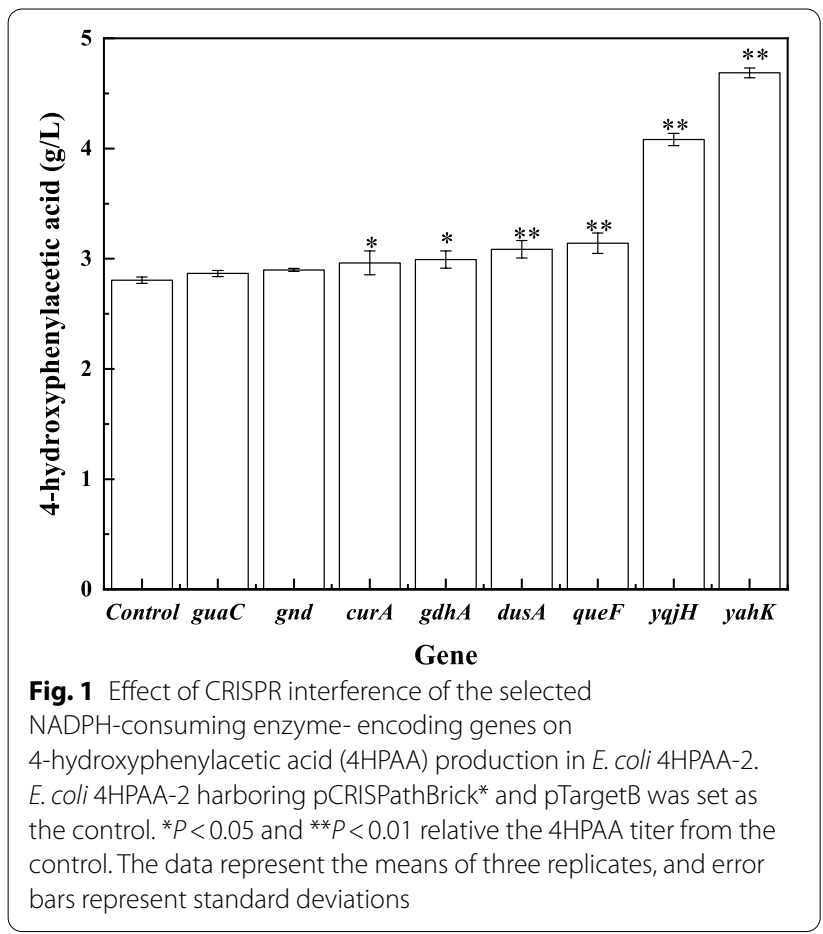


into aromatic alcohol 2(4-hydroxyphenyl)ethanol [1]. This indicates that YahK can compete with 4HPAA biosynthesis for the consumption of 4-hydroxyphenylacetaldehyde. Thus, repression of the $y a h K$ gene increased the availability of 4-hydroxyphenylacetaldehyde for the production of 4HPAA. The $y q j H$ gene encodes NADPHdependent ferric siderophore reductase. YqjH has ferric reductase activity and is required for iron homeostasis in E. coli [24]. The gdhA gene encodes NADPH-dependent glutamine dehydrogenase, which catalyzes the reversible oxidative deamination of glutamate to alpha-ketoglutarate and ammonia. Alper et al. reported that knockout of the $g d h A$ gene improved the production of lycopene by increasing the availability of NADPH [25].

\section{Effects of ATP-consuming enzyme-encoding genes}

There are 400 genes encoding ATP-consuming enzymes in the $E$. coli genome. We constructed sgRNA-expressing plasmids of these genes and cotransferred them with the dCas9" plasmid into E. coli 4HPAA-2 to repress their expression for shake-flask analysis of 4HPAA production. As shown in Table 1 and Additional file 1: Fig. S4, CRISPRi-based repression of 19 genes resulted in an increase in the production of 4HPAA by $9-38 \%$. These genes include purC, araH, yeaG, sucC, $d p p D$, artP, fecE, $\operatorname{artM}, \operatorname{argB}, m g t A$, aas, sapF, nanK, phnN, pfkA, ssuC, $\operatorname{atp} G, \operatorname{cop} A$ and hisP. Of them, 9 genes encode transport protein genes, such as $\operatorname{araH}, d p p D$, artP, fecE, artM, $m g t A$, sapF, ssuC and hisP. In addition to increasing ATP availability, CRISPRi-based repressions may be beneficial to the transport of substrates, enhancing the production of 4HPAA. Recently, transporter engineering has been demonstrated to be a powerful strategy for improving the transmembrane transfer efficiency, protecting cells from toxic compounds, and enhancing microbial production [26]. The biosynthesis of arginine and aromatic amino acids requires glutamic acid. CRISPRi-based repression of the $\arg B$ gene decreased the expression level of the biosynthetic pathway of arginine, increasing glutamic acid availability for 4HPAA production.

To demonstrate the CRISPRi-based repression effect, we also analyzed the transcription levels of some genes after the CRISPRi-based repression. The sgRNAs were able to bind with their respective targets with the different efficiencies ranging from 63 to $80 \%$ repression due to the different genes (Additional file 1: Table 1). This result

Table 1 Effect of CRISPR interference of the selected ATP-consuming enzyme-encoding genes on 4HPAA production in E. coli 4HPAA2

\begin{tabular}{|c|c|c|}
\hline Gene & Description & Ratio* \\
\hline purC & $\begin{array}{l}\text { Phosphoribosylaminoimidazole-succinocarboxamide synthase. It catalyzes the reaction: ATP }+5 \text {-amino-1-(5-phospho-D-ribosyl) } \\
\text { imidazole-4-carboxylate }+ \text { L-aspartate } \rightarrow \text { ADP }+5^{\prime} \text {-phosphoribosyl-4-(N-succinocarboxamide)-5-aminoimidazole }+ \text { phos- } \\
\text { phate }+\mathrm{H}^{+}\end{array}$ & $1.38 \pm 0.02$ \\
\hline $\mathrm{araH}$ & Arabinose $\mathrm{ABC}$ transporter membrane subunit & $1.36 \pm 0.04$ \\
\hline yeaG & Protein kinase & $1.35 \pm 0.03$ \\
\hline sucC & Succinyl-CoA synthetase subunit $\beta$. It catalyzes the reaction: succinate + ATP + coenzyme $A \leftrightarrow$ succinyl-CoA + ADP + phosphate & $1.34 \pm 0.01$ \\
\hline$d p p D$ & Dipeptide ABC transporter ATP-binding subunit & $1.33 \pm 0.02$ \\
\hline $\operatorname{art} P$ & L-Arginine ABC transporter ATP-binding subunit & $1.33 \pm 0.02$ \\
\hline fecE & ferric citrate ABC transporter ATP-binding subunit & $1.33 \pm 0.03$ \\
\hline artM & L-Arginine ABC transporter membrane subunit & $1.30 \pm 0.02$ \\
\hline $\arg B$ & Acetylglutamate kinase. It catalyzes the reaction: $N$-acetyl-L-glutamate + ATP $\rightarrow N$-acetylglutamyl-phosphate + ADP & $1.30 \pm 0.02$ \\
\hline mgtA & $\mathrm{Mg}^{2+}$ importing P-type ATPase & $1.24 \pm 0.02$ \\
\hline aas & Acyltransferase. It has long-chain fatty acid-CoA/long-chain fatty acid [acyl-carrier-protein] ligase activity & $1.22 \pm 0.03$ \\
\hline sapF & Putrescine ABC exporter ATP-binding protein & $1.21 \pm 0.02$ \\
\hline nank & $\begin{array}{l}\mathrm{N} \text {-Acetylmannosamine kinase. It catalyzes the reaction: N-acetyl-D-mannosamine }+\mathrm{ATP} \rightarrow \mathrm{N} \text {-acetyl-D-mannosamine 6-phos- } \\
\text { phate }+\mathrm{ADP}+\mathrm{H}^{+}\end{array}$ & $1.20 \pm 0.03$ \\
\hline phnN & $\begin{array}{l}\text { Ribose 1,5-bisphosphate phosphokinase, It catalyzes the reaction: a-D-ribose 1,5-bisphosphate }+ \text { ATP } \leftrightarrow \text { 5-phospho-a-D-ribose } \\
\text { 1-diphosphate + ADP }\end{array}$ & $1.18 \pm 0.02$ \\
\hline pfkA & $\begin{array}{l}\text { 6-Phosphofructokinase 1. It catalyzes the reaction: } \beta \text {-D-fructofuranose 6-phosphate }+ \text { ATP } \rightarrow \text { ADP }+\beta \text {-D-fructose 1,6-bisphos- } \\
\text { phate }+\mathrm{H}^{+}\end{array}$ & $1.18 \pm 0.02$ \\
\hline ssuC & Aliphatic sulfonates transport permease protein & $1.17 \pm 0.02$ \\
\hline $\operatorname{atpG}$ & ATP synthase F1 complex subunit $y$ & $1.15 \pm 0.01$ \\
\hline copA & Soluble $\mathrm{Cu}^{+}$chaperone & $1.11 \pm 0.01$ \\
\hline hisP & Histidine/lysine/arginine/ornithine transport ATP-binding protein & $1.09 \pm 0.03$ \\
\hline
\end{tabular}

The data represent the means of three replicates, and error bars represent standard deviations 
also demonstrates that the CRISPRi system is effective for gene repression.

Six NADPH-consuming and 19 ATP-consuming enzyme genes were identified using the CECRiS strategy. Moreover, these genes are not present in the 4HPAA biosynthetic pathway and are non-obvious target genes that could be manipulated for the enhanced production of the desired bioproduct. Of them, 9 genes ( $\operatorname{araH}, d p p D$, $\operatorname{artP}$, fecE, artM, $m g t A, s a p F, s s u C$ and hisP) encode transport protein genes. Recently, transporter engineering has been successfully used to improve the production of metabolites. Overexpression of transporters is a common strategy of transporter engineering for improving the production of the desired product [26]. However, there are some native transporters that facilitate the reuptake of final products, reducing the yield of microbial cells. Therefore, these native transporters must be inactivated to avoid product reuptake. Rodriguez et al. reported that the transcriptional levels of some transporter genes were downregulated [27]. The knockout of some of the transporters triggered a $20-50 \%$ improvement in the production of p-coumaric acid.

\section{Synergistic effects of NADPH-consuming}

\section{and ATP-consuming enzyme-encoding genes}

4HPAA has high toxicity to E. coli. Thus, we applied genome shuffling to obtain a shuffled strain $E$. coli 4HPAA-GS-2-4, with a higher tolerance to 4HPAA and titer (Additional file 1: Fig. S5). The above results demonstrate that CRISPRi-based repression of some genes encoding ATP- and NADPH-consuming enzymes improved the production of 4HPAA in E. coli 4HPAA2. In order to determine whether the CRISPRi-based repression of these genes in the shuffled E. coli 4HPAAGS-2-4 strain had the same results, we selected some genes whose 4HPAA titer was increased above 30\% after CRISPRi in E. coli 4HPAA-2 and then investigated their effect in the shuffled strain E. coli 4HPAA-GS-2-4. As shown in Fig. 2, CRISPRi-based repression of yahK, $y q j H, a r a H, a r t P, d p p, f e c E, p u r C, s u c C$ and yea $G$ in $E$. coli 4HPAA-GS-2-4 also increased the production of 4HPAA by $5 \%-14 \%$. Additionally, CRISPRi-based repression did not affect growth, as shown in Fig. 2. This indicates that these genes can be deleted in the rest of the study.

To investigate the synergistic effects of NADPH-consuming and ATP-consuming enzyme-encoding genes, two NADPH-consuming ( $y a h K$ and $y q j H)$ and ATP-consuming ( $a r a H$ and $f e c E$ ) enzyme-encoding genes with the highest yield increase after CRISPRi-based repression were selected. We assembled the sgRNA-expressing vector harboring the N20 sequence of two genes. As shown in Fig. 3, the repression of the single, double and three genes increased the production of 4 HPAA by $11-15$,

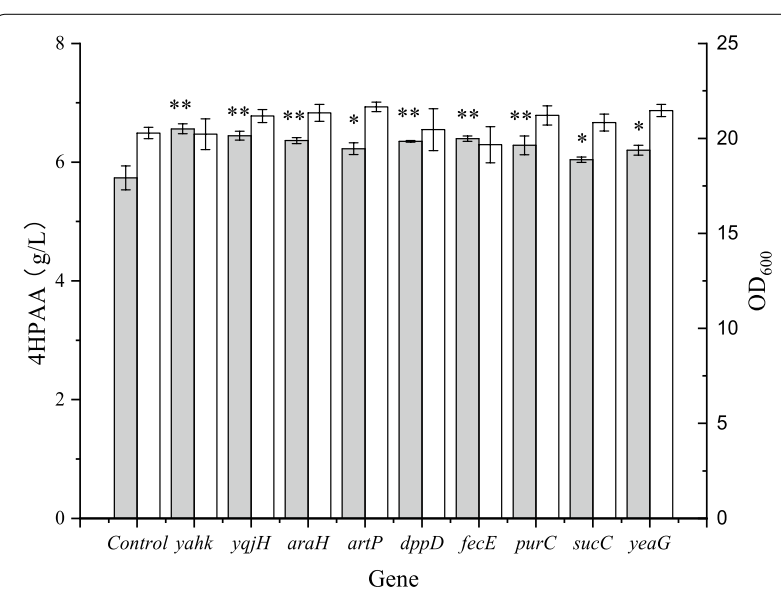

Fig. 2 Effect of CRISPR interference of the selected genes on growth (white bar) and 4HPAA production (gray bar) in E. coli 4HPAA-GS-2-4. E. coli $4 \mathrm{HPAA}-2$ harboring $\mathrm{pCRISPathBrick}{ }^{*}$ and $\mathrm{pTarget} B$ was set as the control. ${ }^{*} P<0.05$ and ${ }^{* *} P<0.01$ relative the 4HPAA titer from the control. The data represent the means of three replicates, and error bars represent standard deviations

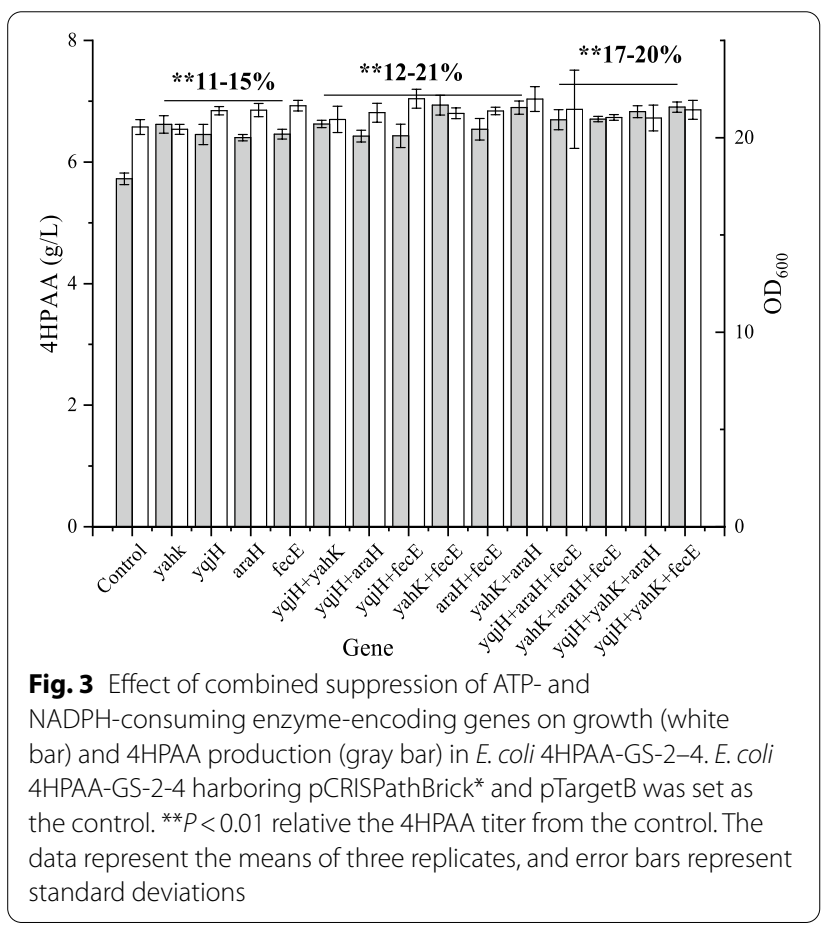

$12-21$ and $17-20 \%(P<0.01)$, respectively. Of them, the combined repression of the $y a h K$ and $f e c E$ had the strongest positive effect for the production of 4HPAA.

To avoid the metabolic burden caused by the dcas9and sgRNA-expressing vectors, $y a h K$ and $f e c E$ in $E$. coli 4HPAA-GS-2-4 were deleted, and the production of the deletion strains was assayed. As shown in Fig. 4, the 


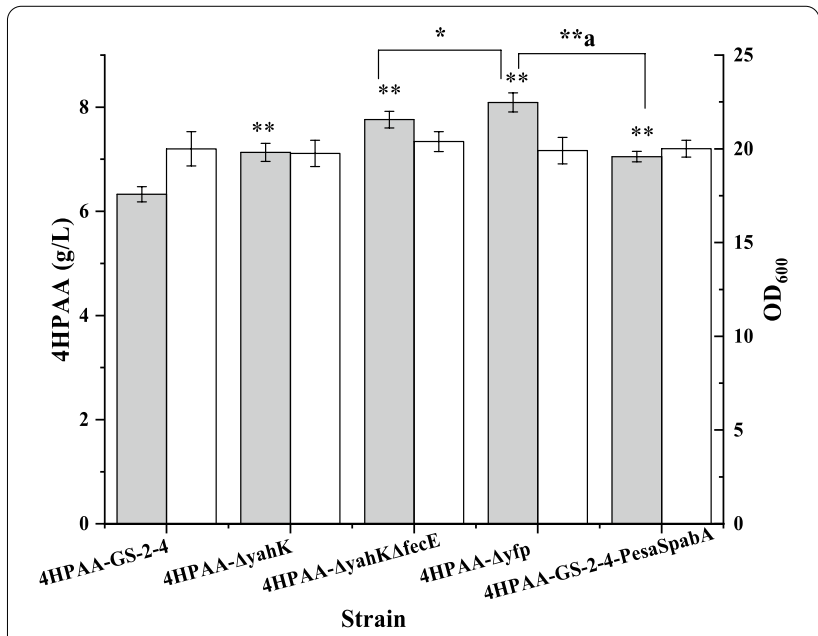

Fig. 4 Effect of gene knockout on growth (white bar) and 4HPAA production (gray bar). ${ }^{*} P<0.05$ relative the 4 HPAA titer from $4 \mathrm{HPAA}-\triangle \mathrm{yahK} \triangle \mathrm{fec} E .{ }^{* *}$ and ${ }^{* * a} P<0.01$ relative the $4 \mathrm{HPAA}$ titer from 4HPAA-GS-2-4 and 4HPAA-GS-2-4-P esas-pabA, respectively. The data represent the means of three replicates, and error bars represent standard deviations deletion of the NADPH-consuming enzyme-encoding gene $y a h K$ increased the production of 4HPAA to $7.13 \pm 0.17$ from $6.32 \pm 0.15 \mathrm{~g} / \mathrm{L}$. Moreover, the 4HPAA titer of the $y a h K$ knockout was slightly higher than that obtained by the $y a h K$ knockdown. It may be because the CRISPRi cannot complete repression the expression of the $y a h K$ (only $63 \%$ repression, Additional file 1: Table 1). The deletion of the ATP-consuming enzyme-encoding gene $f e c E$ in the $y a h K$ knockout further improved the production of 4HPAA to $7.76 \pm 0.16 \mathrm{~g} / \mathrm{L}$.

\section{Dynamic regulation of an essential gene using quorum-sensing (QS)-repressing system}

Yang et al. reported that the $p a b A$ gene encoding aminodeoxychorismate synthase subunit 2 should be knocked down for L-tyrosine derivatives phenylpropanoid (resveratrol and naringenin) production using synthetic small regulatory RNAs [28]. PaBA catalyzes the synthesis of aminobenzoate from chorismate involved in the tetrahydrofolate (vitamin B9) biosynthetic pathway. It also competes for chorismate with 4HPAA biosynthesis. Moreover, synthesizing tetrahydrofolate from chorismate also requires consuming both ATP and NADPH. Thus, we investigated whether knocking down or out this gene also improves the production of 4HPAA. Deleting this gene results in a tetrahydrofolate auxotrophic phenotype. To overcome this problem, we applied an Esa QS-repressing system to downregulate the expression of the pabA gene. In our previous paper [13], we reported an Esa QS-repressing

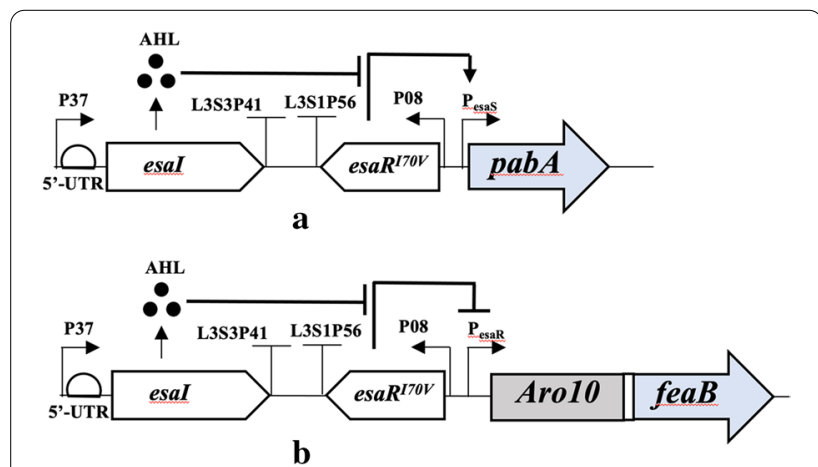

Fig. 5 Quorum-sensing (QS) regulation system in E. coli

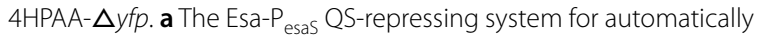
downregulating the expression of the $p a b A$ gene based on cell density. At low cell density, the $p a b A$ gene controlled by $P_{\text {esas }}$ expresses. At high cell densities, the pabA gene controlled by $P_{\text {esas }}$ does not express. $\mathbf{b}$ The Esa-P $\mathrm{P}_{\text {esa }} \mathrm{QS}$ activation system for automatically upregulating the expression of the heterologous 4 HPAA biosynthetic pathway. At low cell density, the 4HPAA biosynthetic pathway gene cluster controlled by $\mathrm{P}_{\text {esaR }}$ does not express. At high cell densities, the 4HPAA biosynthetic pathway gene cluster controlled by $\mathrm{P}_{\text {esar }}$ expresses

system from Pantoea stewartii that consists of esaI, $e s a R^{170 \mathrm{~V}}$ and the $\mathrm{P}_{\text {esas }}$ promoter. The native promoter of the $p a b A$ gene in E. coli $4 \mathrm{HPAA}-\Delta \mathrm{yahK} \Delta \mathrm{fecE}$ was replaced with the Esa- $\mathrm{P}_{\text {esaS }}$ QS-repressing system to obtain E. coli $4 \mathrm{HPAA}-\Delta$ yfp. The concentration of the QS signaling molecule (3-oxohexanoyl-homoserine lactone, AHL) produced by the AHL synthase EsaI is low at low cell density and increases with the cell density. At low cell density, $\mathrm{P}_{\text {esas }}$ is activated by $\mathrm{EsaR}^{\mathrm{I70 \textrm {V }}}$, driving the $p a b A$ gene expression. As cell density increases, the AHL accumulates, resulting in disruption of the transcriptional regulator EsaR ${ }^{170 \mathrm{~V}}$ binding and repression of the transcription of the pabA gene (Fig. 5a). In other words, the transcription level of the pabA decreased with cell growth. As shown in Fig. 4, knocking down the $p a b A$ gene with the Esa- $\mathrm{P}_{\text {esaS }}$ QS-repressing system in $E$. coli $4 \mathrm{HPAA}--\Delta$ yahK $\Delta$ fecE further improved the production of 4HPAA to $8.09 \pm 0.18$ from $7.76 \pm 0.16 \mathrm{~g} / \mathrm{L}(P<0.05)$. To avoid the aromatic amino acid auxotrophic phenotype caused by the deletion of shikimate kinase encoded by $\operatorname{aroK}$ and $\operatorname{aroL}$, the Esa$\mathrm{P}_{\text {esaS }}$ QS-repressing system from $P$. stewartii was also used to dynamically downregulate AroK to increase the titer of shikimate in E. coli from a previously unmeasurable amount to $105 \mathrm{mg} / \mathrm{L}$ [29]. In the $\operatorname{aroK}$ and $\operatorname{aroL}$ knockout strain, the aro $K$ transcription was dynamically downregulated using the Esa- $\mathrm{P}_{\text {esas }}$ QS-repressing system with cell growth. Therefore, this resulting strain can grow in minimal medium without aromatic amino acid supplementation and accumulate shikimate. 
To avoid the auxotrophic phenotype caused by the knockout of the pabA gene, the Esa- $\mathrm{P}_{\text {esaS }}$ QS-repressing system was used to automatically downregulate the expression of the pabA gene based on cell density in this study. This QS-repressing system was also used to dynamically downregulate the competitive glycolysis pathway, resulting in increases in the production of myo-inositol and glucaric acid of up to 5.5- and 4-fold, respectively [29]. Our final E. coli 4HPAA- $\Delta$ yfp strain has a bifunctional QS system (Fig. 5). The Esa-P esaR QS activation system was used to automatically upregulate the expression of the heterologous 4HPAA biosynthetic pathway (Fig. 5b), and the Esa-P ${ }_{\text {esaS }}$ QS-repressing system was used to automatically downregulate the expression of the $p a b A$ gene based on cell density (Fig. 5a). This bifunctional QS system was also applied to the production of 5-aminolevulinic acid and poly-b-hydroxybutyrate, leading to 6- and 12-fold titers, respectively [30].

To investigate the relationship between ATP/or NADPH availability and the production of 4HPAA, we also assayed the intracellular ATP and NADPH concentrations. As shown in Fig. 6, the double knockouts of $y a h K$ and $f e c E$ increased the intracellular NADPH and ATP concentrations to $380.93 \pm 36.52$ and $152.22 \pm 6.39 \mu \mathrm{M}$ from $305.28 \pm 17.82$ and $55.30 \pm 4.13 \mu \mathrm{M}$, respectively. The knockdown of the $p a b A$ gene with the Esa- $\mathrm{P}_{\text {esaS }}$ QS-repressing system further increased the intracellular NADPH and ATP concentrations. This is because tetrahydrofolate biosynthesis from chorismate requires NADPH, ATP and glutamate. Moreover, the dynamic downregulation of the $p a b A$ gene also increased glutamate availability for the production of 4HPAA.

To evaluate the 4HPAA production of E. coli 4HPAA$\Delta y f p$, fed-batch was performed in a 2 -L bioreactor (Fig. 7). This engineered strain produced the highest level of 4HPAA of $28.57 \mathrm{~g} / \mathrm{L}$ with a yield of $27.64 \%$ (mol/ $\mathrm{mol}$ ) at $72 \mathrm{~h}$. This titer and yield were higher than those reported in our previous paper [13]. As shown in Fig. 7, the $\mathrm{OD}_{600}$ value reached 160.65 , which is an approximately threefold increase compared to values reported in our previous paper [13]. This is because this strain is derived from the 4HPAA-tolerant strain E. coli 4HPAA-2.

\section{Conclusion}

We developed a CECRiS strategy for the metabolic engineering of microorganisms. Some target genes were first identified and then deleted or knocked down using the Esa-P ${ }_{\text {esaS }}$ QS-repressing system. This strategy was used to improve NADPH and/or ATP availability, enhancing the production of 4HPAA. After CRISPRi screening, 6 NADPH-consuming and 19 ATP-consuming enzyme genes were identified. The deletion of the NADPHconsuming enzyme-encoding gene $y a h K$ and the
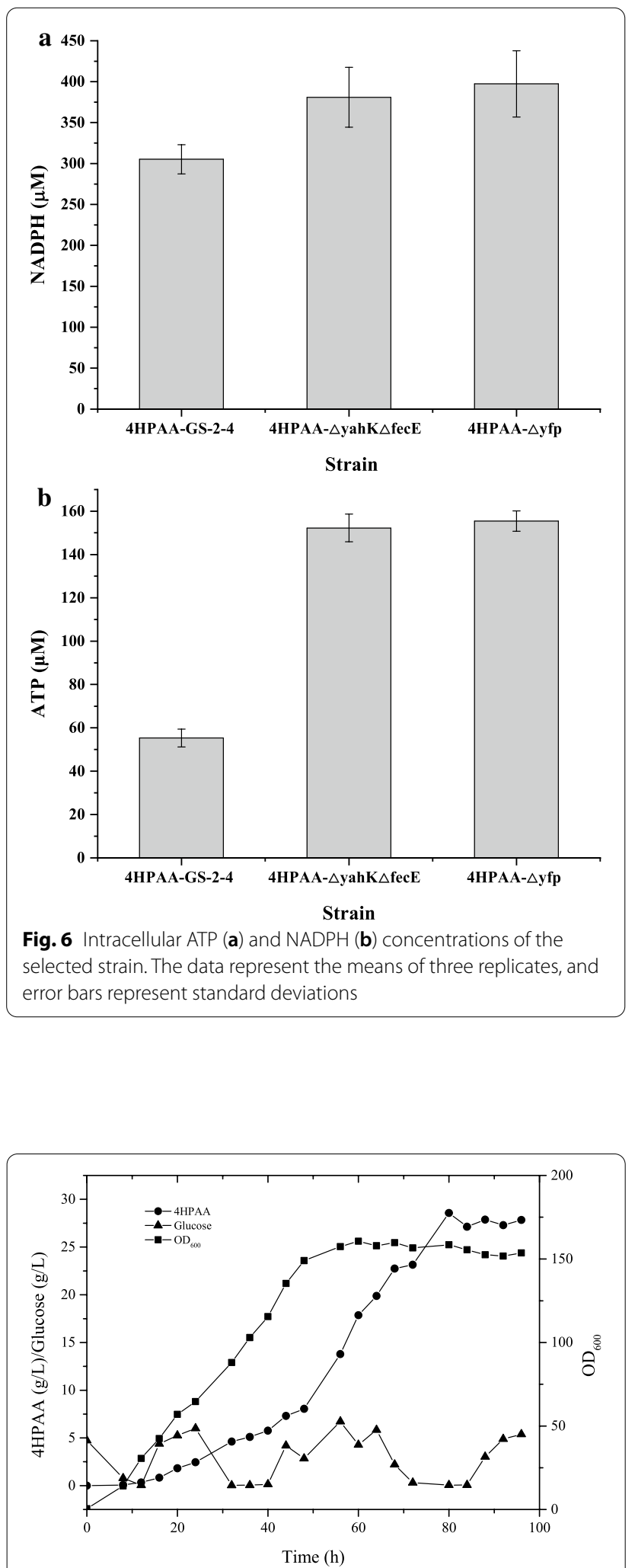

Fig. 7 Fed-batch fermentation of E. coli 4HPAA- $\triangle y f p$. Growth 4HPAA concentration $(\mathbf{O})$; glucose concentration $(\boldsymbol{\Delta})$. Experiments were conducted in duplicate, and measurements are presented as the means with standard deviations 
ATP-consuming enzyme-encoding gene $f e c E$ increased the production of 4 HPAA by $22.8 \%$. Automatically downregulating the expression of the $p a b A$ gene using the Esa- $\mathrm{P}_{\text {esas }} \mathrm{QS}$-repressing system further improved the production of 4HPAA. The final strain E. coli 4HPAA$\Delta$ yfp produced $28.57 \mathrm{~g} / \mathrm{L} 4 \mathrm{HPAA}$ with a yield of $27.64 \%$ $(\mathrm{mol} / \mathrm{mol})$ after $72 \mathrm{~h}$ of fermentation under fed-batch conditions. The titer and yield are the highest values to date. This CECRiS strategy will be useful in engineering microorganisms for the high-level production of bioproducts.

\section{Methods}

\section{Strains, plasmids and primers}

The bacterial strains and plasmids used in this study are listed in Table 2. The primers used in this study are presented in Additional file 1: Table 2.

\section{Construction of the CRISPRi system}

A CRISPRi system was used to repress gene expression as previously described [23].

The N20 sequence was designed to target the $5^{\prime}$ end of the gene (approximately 100 bp downstream of ATG) on the nontemplate DNA strand as previously described [18, 21-23]. sgRNA-X was amplified from pTargetB (Additional file 1: Fig. S6) using primers SpeI-TargetX/EcoRI$B g l \mathrm{II}$-TargetR and then inserted into the SpeI/EcoRI sites of pTargetB to obtain the sgRNA plasmid pTargetB-X. pCRISPathBrick*" (Additional file 1: Fig. S6) and pTargetB-X were cotransferred into $E$. coli cells for the repression of genes.

\section{Knockout or replacement of gene}

Gene knockout or replacement was performed according to the CRISPR-Cas method as previously described $[23,31,34]$. The sgRNA plasmid pTargetB-X for knockout or replacement was obtained as described above for the CRISPRi system. The target fragment for knockout or replacement was amplified by overlap PCR and then inserted into EcoRI/SalI-digested pTargetB-X to obtain pTargetB-X. pCas* and pTargetB-X were cotransferred into E. coli cells to knock out or replace the corresponding gene.

\section{Production of 4HPAA}

A single colony was picked from the plates and grown in a Falcon tube containing $5 \mathrm{~mL}$ of LB medium at $30{ }^{\circ} \mathrm{C}$ and $200 \mathrm{rpm}$ overnight. The resulting seed culture was then inoculated into $250-\mathrm{mL}$ flasks containing $50 \mathrm{~mL}$ of fermentation medium $(10 \mathrm{~g} / \mathrm{L}$ tryptone, $5 \mathrm{~g} / \mathrm{L}$ yeast extract, $10 \mathrm{~g} / \mathrm{L} \mathrm{NaCl}, 40 \mathrm{~g} / \mathrm{L}$ glucose, $0.6 \mathrm{~g} / \mathrm{L} \mathrm{KH}_{2} \mathrm{PO}_{4}$, $2.56 \mathrm{~g} / \mathrm{L} \mathrm{Na} \mathrm{NPO}_{4} \cdot 7 \mathrm{H}_{2} \mathrm{O}$ and $10 \mathrm{~mL} / \mathrm{L}$ trace element solution) with a starting $\mathrm{OD}_{600}$ of 0.1 . The trace element solution contained (per liter) $10 \mathrm{~g}$ of $\mathrm{FeSO}_{4} \cdot 7 \mathrm{H}_{2} \mathrm{O}$, $2.2 \mathrm{~g}$ of $\mathrm{ZnSO}_{4} \cdot 7 \mathrm{H}_{2} \mathrm{O}, 0.58 \mathrm{~g}$ of $\mathrm{MnSO}_{4} \cdot 4 \mathrm{H}_{2} \mathrm{O}, 1 \mathrm{~g}$ of $\mathrm{CuSO}_{4} \cdot 5 \mathrm{H}_{2} \mathrm{O}, 0.1 \mathrm{~g}$ of $\left(\mathrm{NH}_{4}\right)_{6} \mathrm{Mo}_{7} \mathrm{O}_{24} \cdot 4 \mathrm{H}_{2} \mathrm{O}$ and $0.2 \mathrm{~g}$ of $\mathrm{Na}_{2} \mathrm{~B}_{4} \mathrm{O}_{7} \cdot 10 \mathrm{H}_{2} \mathrm{O}$. The $\mathrm{pH}$ of the medium was adjusted to 7.0. The main cultures were incubated at $30{ }^{\circ} \mathrm{C}$ and $200 \mathrm{rpm}$ for $72 \mathrm{~h}$.

Fed-batch fermentation was performed in a 2-L fermenter (MiniBox 2 L*2 Parallel Bioreactor System, T\&J Bioengineering (Shanghai) Co. LTD, Shanghai, China) containing $1.2 \mathrm{~L}$ of fermentation medium with an initial

Table 2 Strains and plasmids used in this study

\begin{tabular}{|c|c|c|}
\hline Name & Description & $\begin{array}{l}\text { Source/ } \\
\text { purpose }\end{array}$ \\
\hline \multicolumn{3}{|l|}{ Strain } \\
\hline E. coli DH5a & supE44 $\triangle($ lacZYA-argF) U169 (Ф80lacZ $\triangle M 15)$ hsdR17 recA endA1 gyrA96 thi-1 relA1 & $\begin{array}{l}\text { Invitro- } \\
\text { gen }\end{array}$ \\
\hline E. coli 4HPAA-2 & 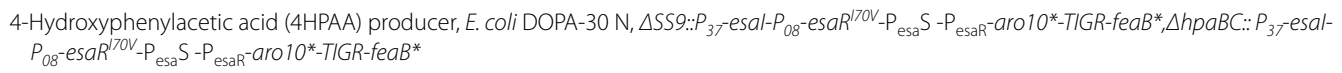 & Lab stock \\
\hline E. coli 4HPAA-GS-2-4 & $\begin{array}{l}\text { 4HPAA overproducer tolerant to } 35.0 \mathrm{~g} / \mathrm{L} \text { 4HPAA with higher 4HPAA titer than E. coli 4HPAA-2 obtained after ARTP mutagenesis and } \\
\text { genome shuffling }\end{array}$ & Lab stock \\
\hline E. coli 4HPAA-- $\triangle$ yahK & 4HPAA overproducer, E. coli 4HPAA-GS-2-4, - $\mathrm{y}$ ahK & $\begin{array}{l}\text { This } \\
\text { study }\end{array}$ \\
\hline $\begin{array}{l}\text { E. coli 4HPAA-- } \triangle \text { yahK } \\
\qquad \text { fecE }\end{array}$ & 4HPAA overproducer, E. coli 4HPAA-GS-2-4,- $\triangle \mathrm{yahK}, \Delta \mathrm{fecE}$ & $\begin{array}{l}\text { This } \\
\text { study }\end{array}$ \\
\hline $\begin{array}{l}\text { E. coli } 4 \text { HPAA-GS- } \\
\text { 2-4-P esas-pabA }\end{array}$ & 4HPAA overproducer, E. coli 4HPAA-GS-2-4, $P_{\text {pabA }}: P_{37}$-esal-P $P_{08}$-esaR ${ }^{l 70 V}{ }_{-} P_{\text {esa }} S$ & $\begin{array}{l}\text { This } \\
\text { study }\end{array}$ \\
\hline E. coli 4HPAA- $\triangle \mathrm{yfp}$ & 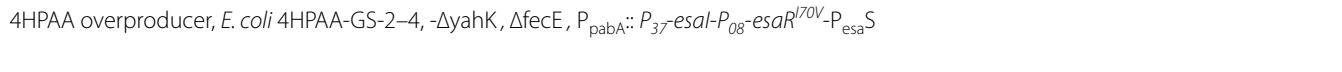 & $\begin{array}{l}\text { This } \\
\text { study }\end{array}$ \\
\hline \multicolumn{3}{|l|}{ Plasmid } \\
\hline pCRISPathBrick* & E. colidcas9 (K848A/K1003A/ R1060A) expression vector & {$[31,32]$} \\
\hline pCas* $^{*}$ & E. colicas9 (K848A/K1003A/ R1060A) expression vector & [31] \\
\hline pTargetB & E. coli sgRNA expression vector, BglBrick vector & [33] \\
\hline
\end{tabular}


$\mathrm{OD}_{600}$ of approximately 0.1 . The temperature was controlled at $30{ }^{\circ} \mathrm{C}$, and the $\mathrm{pH}$ value was maintained at 7.0 by the automatic addition of $\mathrm{NH}_{4} \mathrm{OH}$. The airflow rate was $1.2 \mathrm{~L} / \mathrm{min}$. Dissolved oxygen was kept above $25 \%$ by adjusting the agitation rate from 400 to $1200 \mathrm{rpm}$. A feed solution ( $\mathrm{pH} 7.0$ ) containing (per liter) 500 g glucose and $30 \mathrm{~g} \mathrm{MgSO}_{4} \cdot 7 \mathrm{H}_{2} \mathrm{O}$ was fed continuously to the fermenter using a pH-stat feeding strategy. Once the glucose was depleted, the $\mathrm{pH}$ rose rapidly. When the $\mathrm{pH}$ was greater than 7.1, the feed was automatically added to the fermenter. Samples were periodically withdrawn, and these parameters $\left(\mathrm{OD}_{600}\right.$, residual glucose concentrations and 4HPAA concentrations) were determined.

\section{Assay}

Cell density was monitored by measuring the optical density at $600 \mathrm{~nm}$. 4HPAA in the supernatants was analyzed using an HPLC system (LC-20A, Shimadzu, Japan) with a photodiode array detector (SPD-M20A) at $222 \mathrm{~nm}$ using an Inertsil ODS-SP column $(5 \mu \mathrm{m}, 4.6 \times 150 \mathrm{~mm}$, GL Sciences Inc., Tokyo, Japan), which was kept at $30{ }^{\circ} \mathrm{C}$. The mobile phase was $0.2 \%$ TFA in methanol at a flow rate of $0.5 \mathrm{~mL} / \mathrm{min}$. The methanol concentration was increased from 14 to $45 \%$ for $20 \mathrm{~min}$, decreased to $14 \%$ and then maintained for $10 \mathrm{~min}$. The concentration of 4HPAA was quantified by the standard curve method. Glucose concentrations were determined using a glucose assay kit (Shanghai Rongsheng Biotech Corporation, Shanghai, China) with glucose oxidase.

\section{Assay of intracellular NADPH concentration}

The intracellular NADPH concentration was measured by HPLC as previously described [33, 35]. The cells cultured for $44 \mathrm{~h}$ were immediately chilled in an ice bath, centrifuged at $5200 \times \mathrm{g}$ for $10 \mathrm{~min}$ and then resuspended in $1 \mathrm{~mL}$ of deionized water to a final $\mathrm{OD}_{600}$ of 30 . Then, $500 \mu \mathrm{L}$ of $0.3 \mathrm{M} \mathrm{NaOH}$ was added, incubated at $60{ }^{\circ} \mathrm{C}$ for $10 \mathrm{~min}$, and neutralized by $500 \mu \mathrm{L}$ of $0.3 \mathrm{M} \mathrm{HCl}$ and $100 \mu \mathrm{L}$ of Tricine- $\mathrm{NaOH}$ (pH 8.0). The neutralized samples were centrifuged at $12,000 \times \mathrm{g}$ and $4{ }^{\circ} \mathrm{C}$ for $20 \mathrm{~min}$, and the resulting supernatants were filtered through a $0.22-\mu \mathrm{m}$ membrane. The concentrations of NADPH were determined using an HPLC system (LC-20A HPLC, Shimadzu, Japan) equipped with an Inertsil ODS-SP column (5 $\mu \mathrm{m}, 4.6 \times 150 \mathrm{~mm}$, GL Sciences Inc., Tokyo, Japan), which was kept at $30{ }^{\circ} \mathrm{C}$ and detected at $254 \mathrm{~nm}$. The mobile phase composed of A $(0.2 \mathrm{M}$ phosphate buffer containing $10 \mathrm{mM}$ tetrabutylammonium bromide, $\mathrm{pH}$ 7.0) and $\mathrm{B}$ (methanol) at a ratio of 80:20 with a flow rate of $0.8 \mathrm{~mL} / \mathrm{min}$. The concentration of NADPH was quantified by the standard curve method.

\section{Assay of intracellular ATP concentration}

The intracellular ATP concentration was determined by HPLC [36]. The cells cultured for $44 \mathrm{~h}$ were immediately cooled in an ice bath, centrifuged at $5200 \times \mathrm{g}$ for $10 \mathrm{~min}$, resuspended in $6 \%$ perchloric acid to a final $\mathrm{OD}_{600}$ of 30 , ultrasonically broken in an ice bath and then neutralized with $0.6 \mathrm{~mL}$ of saturated $\mathrm{K}_{2} \mathrm{CO}_{3}$. The solution was then centrifuged at $12,000 \times \mathrm{g}$ and $4{ }^{\circ} \mathrm{C}$ for $20 \mathrm{~min}$, and the resulting supernatants were filtered through a 0.22 $\mu \mathrm{m}$ membrane. The concentrations of ATP were determined using an HPLC system (LC-20A HPLC, Shimadzu, Japan) equipped with an Inertsil ODS-SP column $(5 \mu \mathrm{m}$, $4.6 \times 150 \mathrm{~mm}$, GL Sciences Inc., Tokyo, Japan), which was kept at $30{ }^{\circ} \mathrm{C}$ and detected at $254 \mathrm{~nm}$. The mobile phase was phosphate buffer containing $0.06 \mathrm{M} \mathrm{K}_{2} \mathrm{HPO}_{4}$ and $0.04 \mathrm{M} \mathrm{KH}_{2} \mathrm{PO}_{4}(\mathrm{pH} 7.0)$ with a flow rate of $1.0 \mathrm{~mL} /$ min. The concentration of ATP was quantified by the standard curve method.

\section{Statistical analysis}

All experiments were carried out three times, and the data were taken as the means \pm standard deviation. Significant differences were determined by Tukey's test using the OriginPro (version 7.5) package. Statistical significance was defined as $p<0.05$.

\section{Supplementary Information}

The online version contains supplementary material available at https://doi. org/10.1186/s13068-021-01954-6.

Additional file 1: Figure S1 Biosynthetic pathway of 4-hydroxyphenylacetic acid in the engineered Escherichia coli used in this study. Black: E. coli genes; red: Saccharomyces cerevisiae gene. PEP: phosphoenolpyruvate; E4P: D-erythrose 4-phosphate; DAHP: 3-deoxy-arabino-heptulonate 7-phosphate; DHQ: 3-dehydroquinate; DHS: 3-dehydroshikimate; EPSP: enolpyruvoyl-shikimate 3-phosphate. aroF/aroH/aroG: 3-deoxy7-phosphoheptulonate synthase gene; aroB: 3-dehydroquinate synthase gene; aroD: 3-dehydroquinate dehydratase gene; aroE: shikimate dehydrogenase gene; aroK/aroL: shikimate kinase gene; aroA: 3-phosphoshikimate 1-carboxyvinyltransferase gene; aroC: chorismate synthase gene; tyrA: chorismate mutase/prephenate dehydrogenase gene; pheA: chorismate mutase/prephenate dehydratase gene; ARO10: phenylpyruvate decarboxylase gene from S. cerevisiae; feaB: phenylacetaldehyde dehydrogenase gene. Figure S2. CRISPRi-based gene repression. (A) Block transcription initiation via competition with RNA polymerase (RNAP) or transcription factors (TFs) for binding to promoter DNA. When the dCas9-sgRNA complex binds to the promoter sequence or the cis-acting transcription factor binding site (TFBS), it can block transcription initiation by sterically inhibiting the binding of RNAP or transcription factors (TFs). Silencing of transcription initiation is effective for both nontemplate (NT) and template (T) DNA strand. (B) Block transcription elongation by targeting the CDS and preventing the transcription elongation complex from passing. When the dCas9-sgRNA complex binds to the NT DNA strand of the UTR or the protein coding region, it can repress gene expression by blocking the elongating RNAPs. Silencing of transcription elongation is effective only for the NT DNA strand. Additionally, the interference is negatively correlated with the distance of the target site from the transcription start site. Thus, to achieve better repression, target sites within the $5^{\prime}$ end of the gene should be selected. Figure S3. Effect 
of repression of NADHP-consuming enzyme-encoding genes on the production of 4HPAA. Figure S4. Effect of repression of ATP-consuming enzyme-encoding genes on the production of 4HPAA. Figure S5. (A) The 4HPAA tolerance of E. coli 4HPAA ( $)$ and E. coli 4HPAA-GS-2-4 (-). Cells were cultured in the presence of $35.0 \mathrm{~g} / \mathrm{L} 4 \mathrm{HPAA}$ at $30^{\circ} \mathrm{C}$ and $200 \mathrm{rpm}$ for $24 \mathrm{~h}$. (B) The 4HPAA production (gray bar) and growth (white bar) of E. coli 4HPAA and E. coli 4HPAA-GS-2-4. Figure S6. Plasmid maps used for CRISPRi in this study. Table S1. Transcriptional levels of the selected genes in E. coli 4HPAA-2 after CRISPRi-based repression compared with those without sgRNAs. Table S2. Primers used in this study.

\section{Acknowledgements}

Not applicable

\section{Authors' contributions}

YPS performed all of the experimental works. YLL and ZBY performed the fedbatch fermentation and the assay. QL and XL constructed the sgRNA plasmids. JZL designed the study and wrote the manuscript. All the authors read and approved the final manuscript.

\section{Funding}

This work was funded by National Key R\&D Program of China (2020YFA0906900), the National Natural Science Foundation of China (Grant No. 31901024 and 21808248), Guangdong Basic and Applied Basic Research Foundation (No. 2018A030310255, 2019B1515210006 and 2019A1515110381), the Open Fund Project of Shenzhen Innovation Institute of Synthetic Biology (DWKF20190003), China Postdoctoral Science Foundation funded project (2019M653160) and the Fundamental Research Funds for the Central Universities, Sun Yat-sen University (19lgpy133 and 20lgpy113) for their financial support.

\section{Availability of data and materials}

Not applicable.

\section{Declarations}

\section{Ethics approval and consent to participate}

Not applicable.

\section{Consent for publication}

Not applicable.

\section{Competing interests}

The authors declare that they have no competing interests.

\begin{abstract}
Author details
${ }^{1}$ Institute of Synthetic Biology, Biomedical Center, Guangdong Province Key Laboratory of Improved Variety Reproduction in Aquatic Economic Animals, School of Life Sciences, Sun Yat-Sen University, Guangzhou 510275, People's Republic of China. ${ }^{2}$ College of Chemistry and Bioengineering, Hunan University of Science and Engineering, Yongzhou 425199, China.
\end{abstract}

Received: 23 December 2020 Accepted: 11 April 2021

Published online: 20 April 2021

\section{References}

1. Koma D, Yamanaka H, Moriyoshi K, Ohmoto T, Sakai K. Production of aromatic compounds by metabolically engineered Escherichia coli with an expanded shikimate pathway. Appl Environ Microb. 2012;78(17):6203-16.

2. Thakur N, Kumar V, Thakur S, Sharma N, Bhalla TC. Biotransformation of 4-hydroxyphenylacetonitrile to 4-hydroxyphenylacetic acid using whole cell arylacetonitrilase of Alcaligenes faecalis MTCC12629. Process Biochem. 2018;73:117-23.

3. Ng TB, Liu F, Lu YH, Cheng CHK, Wang ZT. Antioxidant activity of compounds from the medicinal herb Aster tataricus. Comp Biochem Phys C. 2003;136(2):109-15.
4. Du L, Mei HF, Yin X, Xing YQ. Delayed growth of glioma by a polysaccharide from Aster tataricus involve upregulation of $\mathrm{Bax} / \mathrm{BCl}-2$ ratio, activation of caspase-3/8/9, and downregulation of the Akt. Tumor Biol. 2014;35(3):1819-25.

5. Yen MH, Lee JJ, Yeh CF, Wang KC, Chiang YW, Chiang LC, et al. Yakammaoto inhibited human coxsackievirus B4 (CVB4)-induced airway and renal tubular injuries by preventing viral attachment, internalization, and replication. J Ethnopharmacol. 2014;151(3):1056-63.

6. Vissiennon C, Nieber K, Kelber O, Butterweck V. Route of administration determines the anxiolytic activity of the flavonols kaempferol, quercetin and myricetin - are they prodrugs? J Nutr Biochem. 2012;23(7):733-40.

7. Kim DH, Jung EA, Sohng IS, Han JA, Kim TH, Han MJ. Intestinal bacterial metabolism of flavonoids and its relation to some biological activities. Arch Pharm Res. 1998:21:17-23.

8. Zhao HQ, Jiang ZH, Chang XM, Xue HT, Yahefu W, Zhang XY. 4-Hydroxyphenylacetic acid prevents acute apap-induced liver injury by increasing phase ii and antioxidant enzymes in mice. Front Pharmacol. 2018;9:653.

9. Wen KC, Chang CS, Chien YC, Wang HW, Wu WC, Wu CS, et al. Tyrosol and its analogues inhibit alpha-melanocyte-stimulating hormone induced melanogenesis. Int J Mol Sci. 2013;14(12):23420-40.

10. Liu ZY, Xi RG, Zhang ZR, Li WP, Liu Y, Jin FG, et al. 4-Hydroxyphenylacetic acid attenuated inflammation and edema via suppressing HIF-1 alpha in seawater aspiration-induced lung injury in rats. Int J Mol Sci. 2014;15(7):12861-84.

11. Mutsukado M, Yamada S. Methods for preparing 4-hydroxyphenylacetic acids. United States Patent 14412082; 1983.

12. Vallejos JC, Christidis Y. Preparation process for hydroxyphenylacetic acids United States Patent. US005395964A; 1995.

13. Shen YP, Fong LS, Yan ZB, Liu JZ. Combining directed evolution of pathway enzymes and dynamic pathway regulation using a quorum-sensing circuit to improve the production of 4-hydroxyphenylacetic acid in Escherichia coli. Biotechnol Biofuels. 2019;12:94.

14. Shen YP, Niu FX, Yan ZB, Fong LS, Huang YB, Liu JZ. Recent advances in metabolically engineered microorganisms for the production of aromatic chemicals derived from aromatic amino acids. Front Bioeng Biotech. 2020;8:407.

15. Wang $\mathrm{M}$, Chen $\mathrm{BQ}$, Fang $\mathrm{YM}$, Tan TW. Cofactor engineering for more efficient production of chemicals and biofuels. Biotechnol Adv. 2017;35(8):1032-9.

16. Liu JH, Li HL, Zhao GR, Caiyin QGL, Qiao JJ. Redox cofactor engineering in industrial microorganisms: strategies, recent applications and future directions. J Ind Microbiol Biot. 2018;45(5):313-27.

17. Hara KY, Kondo A. ATP regulation in bioproduction. Microb Cell Fact. 2015;14:198.

18. Larson MH, Gilbert LA, Wang XW, Lim WA, Weissman JS, Qi LS. CRISPR interference (CRISPRi) for sequence-specific control of gene expression. Nat Protoc. 2013:8(11):2180-96.

19. Zhao D, Zhu X, Zhou H, Sun N, Wang T, Bi C, et al. CRISPR-based metabolic pathway engineering. Metab Eng. 2021;63:148-59.

20. Wu YK, Liu YF, LV XQ, Li JH, Du GC, Liu L. Applications of CRISPR in a microbial cell factory: From genome reconstruction to metabolic network reprogramming. ACS Synth Biol. 2020;9(9):2228-38.

21. Lv L, Ren YL, Chen JC, Wu Q, Chen GQ. Application of CRISPRi for prokaryotic metabolic engineering involving multiple genes, a case study: Controllable P(3HB-co-4HB) biosynthesis. Metab Eng. 2015;29:160-8.

22. Wu JJ, Du GC, Chen J, Zhou JW. Enhancing flavonoid production by systematically tuning the central metabolic pathways based on a CRISPR interference system in Escherichia coli. Sci Rep-Uk. 2015. https://doi.org/ 10.1038/srep13477.

23. Lu Q, Liu JZ. Enhanced astaxanthin production in Escherichia coli via morphology and oxidative stress engineering. J Agr Food Chem. 2019;67(42):11703-9.

24. Wang SN, Wu Y, Outten FW. Fur and the novel regulator Yajl control transcription of the ferric reductase gene yajH in Escherichia coli. J Bacteriol. 2011;193(2):563-74.

25. Alper H, Jin YS, Moxley JF, Stephanopoulos G. Identifying gene targets for the metabolic engineering of lycopene biosynthesis in Escherichia coli. Metab Eng. 2005;7(3):155-64.

26. Zhu Y, Zhou C, Wang Y, Li C. Transporter engineering for microbial manufacturing. Biotechnol J. 2020;15(9):1900494. 
27. Rodriguez A, Chen Y, Khoomrung S, Ozdemir E, Borodina I, Nielsen J. Comparison of the metabolic response to over-production of p-coumaric acid in two yeast strains. Metab Eng. 2017:44:265-72.

28. Yan D, Kim WJ, Yoo SM, Choi JH, Ha SH, Lee MH, et al. Repurposing type III polyketide synthase as a malonyl-CoA biosensor for metabolic engineering in bacteria. P Natl Acad Sci USA. 2018;115(40):9835-44.

29. Gupta A, Reizman IMB, Reisch CR, Prather KL. Dynamic regulation of metabolic flux in engineered bacteria using a pathway-independent quorum-sensing circuit. Nat Biotechnol. 2017;35(3):273-9.

30. Gu F, Jiang W, Mu YL, Huang H, Su TY, Luo Y, et al. Quorum sensing-based dual-function switch and its application in solving two key metabolic engineering problems. Acs Synth Biol. 2020;9(2):209-17.

31. Niu FX, He X, Wu YQ, Liu JZ. Enhancing production of pinene in Escherichia coli by using a combination of tolerance, evolution, and modular co-culture engineering. Front Microbiol. 2018;9:1623.

32. Li Z, Liu JZ. Transcriptomic changes in response to putrescine production in metabolically engineered Corynebacterium glutamicum. Front Microbiol. 2017:8:1987.
33. Li Z, Shen YP, Jiang XL, Feng LS, Liu JZ. Metabolic evolution and a comparative omics analysis of Corynebacterium glutamicum for putrescine production. J Ind Microbiol Biot. 2018;45(2):123-39.

34. Jiang Y, Chen B, Duan CL, Sun BB, Yang JJ, Yang S. Multigene editing in the Escherichia coli genome via the crispr-cas9 system. Appl Environ Microb. 2015;81(7):2506-14.

35. Huang D, Yang KX, Liu J, Xu YY, Wang YY, Wang R, et al. Metabolic engineering of Escherichia coli for the production of 2'-fucosyllactose and 3-fucosyllactose through modular pathway enhancement. Metab Eng. 2017:41:23-38

36. Tao S, Qian Y, Wang X, Cao WJ, Ma WC, Chen KQ, et al. Regulation of ATP levels in Escherichia coli using CRISPR interference for enhanced pinocembrin production. Microb Cell Fact. 2018;17:147.

\section{Publisher's Note}

Springer Nature remains neutral with regard to jurisdictional claims in published maps and institutional affiliations.
Ready to submit your research? Choose BMC and benefit from:

- fast, convenient online submission

- thorough peer review by experienced researchers in your field

- rapid publication on acceptance

- support for research data, including large and complex data types

- gold Open Access which fosters wider collaboration and increased citations

- maximum visibility for your research: over $100 \mathrm{M}$ website views per year

At BMC, research is always in progress.

Learn more biomedcentral.com/submissions 